\title{
Effect of melt conditioning on heat treatment and mechanical properties of AZ31 alloy strips produced by Twin Roll Casting
}

\author{
Sanjeev Das ${ }^{\mathrm{a} *}$, N. S. Barekar ${ }^{\mathrm{a}}$, Omer El Fakir ${ }^{\mathrm{b}}$, Liliang Wang ${ }^{\mathrm{b}}$, A. K. Prasada Rao ${ }^{\mathrm{a}}$, \\ J. B. Patel ${ }^{a}$, H. R. Kotadia ${ }^{\mathrm{a}}$, A. Bhagurkar ${ }^{\mathrm{a}}$, John P. Dear ${ }^{\mathrm{b}}$, Z. Fan $^{\mathrm{a}}$ \\ ${ }^{\mathrm{a}}$ The EPSRC Centre - LiME, BCAST, Brunel University, UB8 3PH, UK \\ ${ }^{\mathrm{b}}$ Department of Mechanical Engineering, Imperial College London, South Kensington \\ Campus, London SW7 2AZ, UK
}

\begin{abstract}
In the present investigation, magnesium strips were produced by twin roll casting (TRC) and melt conditioned twin roll casting (MC-TRC) processes. Detailed optical microscopy studies were carried out on as-cast and homogenized TRC and MC-TRC strips. The results showed uniform, fine and equiaxed grain structure was observed for MC-TRC samples in as-cast condition. Whereas, coarse columnar grains with centreline segregation were observed in the case of as-cast TRC samples. The solidification mechanisms for TRC and MC-TRC have been found completely divergent. The homogenized TRC and MC-TRC samples were subjected to tensile test at elevated temperature $\left(250\right.$ to $\left.400^{\circ} \mathrm{C}\right)$. At $250^{\circ} \mathrm{C}$, MC-TRC sample showed significant improvement in strength and ductility. However, at higher temperatures the tensile properties were almost comparable, despite of TRC samples having larger grains compared to MC-TRC samples. The mechanism of deformation has been explained by detailed fractures surface and sub-surface analysis carried out by scanning electron and optical microscopy. Homogenized MC-TRC samples were formed (hot stamping) into engineering component without any trace of crack on its surface. Whereas, TRC samples cracked in several places during hot stamping process.
\end{abstract}

Key words; Twin roll casting, solidification, tensile test, fracture analysis, optical and scanning electron microscopy

*Telephone: +44-7909310243, Fax: +44(0)1895 269758

Email address: sanjeevdas80@gmail.com 


\section{Introduction}

The sheet products of magnesium alloys have a great potential for applications in automotive structures and electronic devices because of their high specific strength. Also they have excellent properties such as heat-dissipation, damping, electro-magnetic shielding and recycling [1-3]. But due to limited ductility, their production is inefficient and expensive [4, 5]. Conventionally, magnesium sheet is produced by continuous /semi continuous direct chill (DC) casting thick slabs, followed by extensive thermo-mechanical processing, leading to high energy consumption, low materials yield and inevitable high cost.

Twin roll casting (TRC) has been demonstrated to be a process capable of producing $\mathrm{Mg}$ sheets by eliminating several processing steps used in conventional sheet making process at significantly reduced cost [6]. TRC process is a combination of casting and hot rolling process. The solidification starts from the surface of the rolls towards the centre of the strip, resulting in solute segregation. Moreover, the combined hot rolling process during TRC develops strong texture for magnesium and its alloys. Therefore, the quality of the $\mathrm{Mg}$ sheets produced by the TRC process is limited by the formation of coarse columnar dendritic grains, centreline segregation and strong basal texture [7], which reduces the strength and ductility of Mg-alloys. Historically, the emphasis of TRC process has been on the rolling aspect of the process, rather than the casting aspect, and hence the above mentioned problems were inevitable. Such considerations gave rise to the construction of large TRC machines to accommodate larger rolls and larger separating forces.

To overcome above mentioned problems, it was believed that the emphasis should be placed on TRC as a casting process, rather than as a rolling process. High quality TRC strip can be produced through implementation of appropriate solidification control without excessive separating force. Deformation is only required in the TRC process, to control the strip thickness, to maintain a good contact between the solidifying strip and the rolls for effective heat transfer, and to deliver adequate surface quality. Therefore, the separating force should be kept to a minimum, as long as the above requirements are satisfied. Solidification in the TRC process should be controlled in such a way that heterogeneous nucleation is enhanced and equiaxed growth is promoted. To enhance heterogeneous nucleation grain refiners (GR) are used. However, addition of GR in the TRC process results in nozzle blockage and upstream nucleation [8]. Also, for the aluminium containing magnesium alloys, there is no effective grain refiner available and there are issues with the contamination of the alloy melt 
and in consistency [9]. Melt conditioning (MC) before TRC is an effective and efficient method to obtain a fine grained microstructure with insignificant basal texture $[10,11]$. MC process assists in disintegration of $\mathrm{MgO}$ particle films/skins and dispersion of $\mathrm{MgO}$ particles in magnesium alloys. These dispersed $\mathrm{MgO}$ particles act as potent nucleation site for $\alpha-\mathrm{Mg}$ phase [9]. Enhanced nucleation by melt conditioning technique alters the solidification mechanism, which may affect the deformation amount during TRC process. The recrystallization kinetics depends on the amount of energy stored inside a sample, which is a function of deformation in the present case.

As mentioned earlier, improvement in strength and formability of wrought magnesium alloy is of great concern for automobile and aerospace industries. Several attempts has been made by various researchers to improve the strength and formability of wrought magnesium by sequential warm rolling [12], thermo-mechanical process [13] and hot rolling [14] processes. Some improvement in strength and ductility has been shown by the researchers, however, these post TRC treatments consumes lot of energy and space, which is also a concern for industries and environment. The aim of the present work is to develop an economical and less energy consuming TRC process to produce high strength formable magnesium alloy strip.

In the present investigation, an attempt has been made to understand the effect of MC process on the solidification mechanism during TRC, which influences the heat treatment response and hence the mechanical properties of the strips.

\section{Experimental}

2.1 TRC and MCTRC process: AZ31 (Mg-3.4Al-0.97Zn-0.31Mn, in wt.\%) commercial alloy was melted in a steel crucible at $700{ }^{\circ} \mathrm{C}$ under a protective atmosphere of $\mathrm{N}_{2}+\mathrm{SF}_{6}$. The melt was then transferred to a twin-screw melt-conditioning unit. The details of twin screw melt conditioning unit can be found elsewhere [11]. A screw rotation speed of $600 \mathrm{rpm}$ was used for intensive shearing of the melt at $640{ }^{\circ} \mathrm{C}$ for 60 seconds. The conditioned melt was fed into a vertical twin-roll casting machine through a pre-heated tundish. The twin-roll caster has a pair of water cooled equal-diameter steel rolls of $100 \mathrm{~mm}$ diameter and $150 \mathrm{~mm}$ width. A protective environment was maintained during the TRC process to prevent oxidation. To protect the liquid $\mathrm{Mg}$ alloy from burning, a constant atmosphere of $\mathrm{N}_{2}+\mathrm{SF}_{6}$ was maintained in the twin-screw melt-conditioning unit and on the tundish. The strip thickness was fixed to 1.7 
$\mathrm{mm}$ and a constant casting speed of $6 \mathrm{~m} / \mathrm{min}$ was employed. Twin roll casting was also carried out under similar conditions without MC, for comparison.

2.2 Homogenization process: The specimens were cut from the strips into identical shape and size. The sharp edges and corners were blunt by grinding to prevent thermal stresses. The specimens were heat treated at $400^{\circ} \mathrm{C}$ for one hour at various time intervals, i.e., $15,30,45$, $60,75,90,105,120,180,240$ minutes, followed by water quenching.

2.3 Mechanical testing: Tensile tests were conducted on a Gleeble 3800 thermo-mechanical simulator, which can heat a specimen by direct resistance heating at a rate as high as 1000 $\mathrm{K} / \mathrm{s}$. The dimensions of the tensile test specimen are given in Fig. 1. Tensile tests were performed to failure at different temperatures $\left(250{ }^{\circ} \mathrm{C}, 300{ }^{\circ} \mathrm{C}, 350{ }^{\circ} \mathrm{C}\right.$ and $\left.400{ }^{\circ} \mathrm{C}\right)$ after the specimens had been soaked at the target temperature for 1 minute. The tests were carried out at constant strain rate of $1 / \mathrm{s}$, representative of typical strain rates in hot forming processes. The strain was measured using a C-Gauge as shown in Fig. 2(a). The test temperature progress is shown in Fig. 2(b).

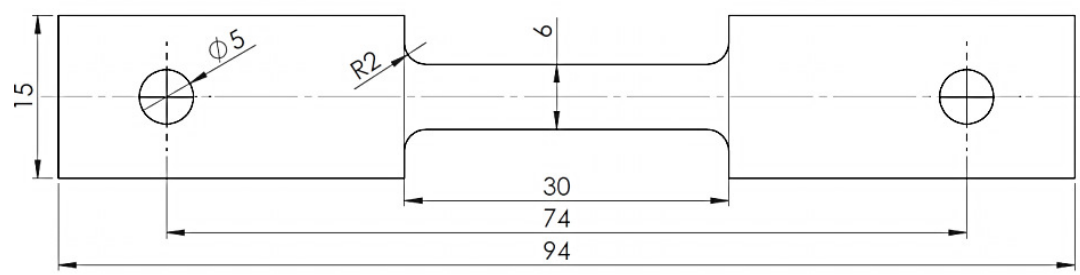

Fig. 1 - Geometry of the tensile test specimens (dimensions in mm) [15]

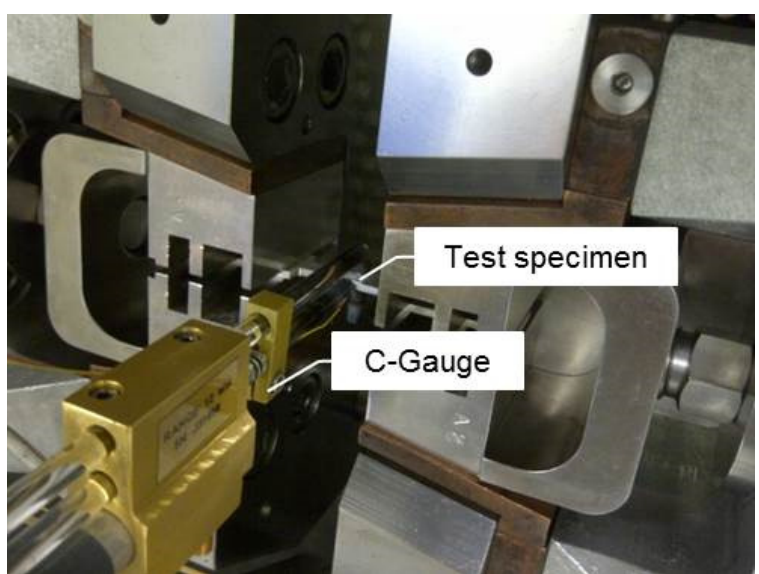

(a)

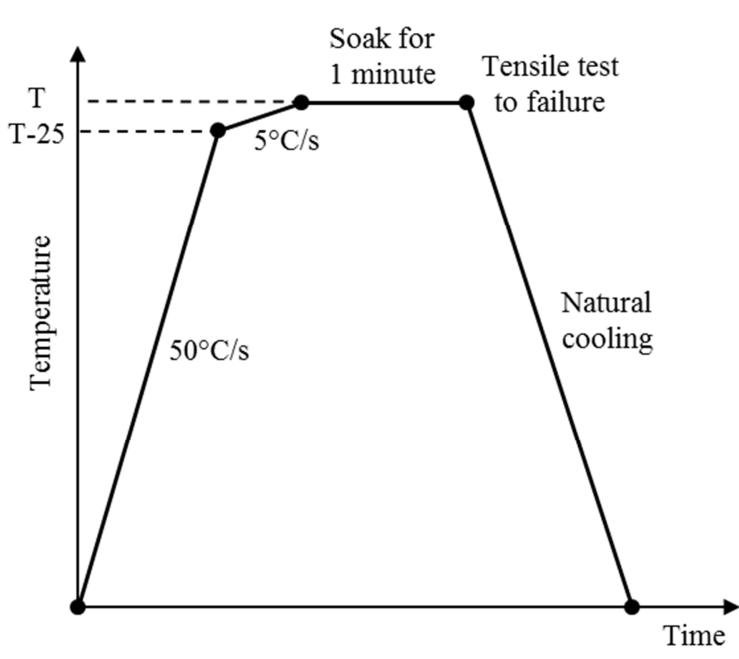

(b)

Fig. 2 - (a) Test specimen setup and (b) test temperature progress [16] 
Hot stamping was performed using the HFQ process at $400^{\circ} \mathrm{C}$ to form component directly from homogenized TRC and MC-TRC strips with a stamping speed of $250 \mathrm{~mm} / \mathrm{s}$, in a tool previously used for producing wing stiffener components, shown in Fig 3(a and b). In this process, the material was heated close to its SHT temperature at which it is most formable, transferred to a cold die, and formed at a high speed. The high forming speed and hence strain rate enhances the work hardening of the material and reduces the incidence of localized necking. This is followed by holding and quenching of the formed part in the die until it is cooled to room temperature, which decreases spring-back and provides a high potential postform strength.

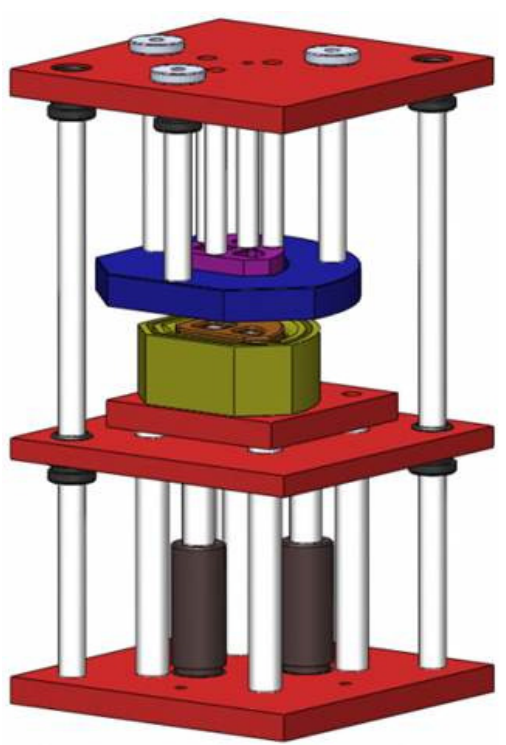

(a)

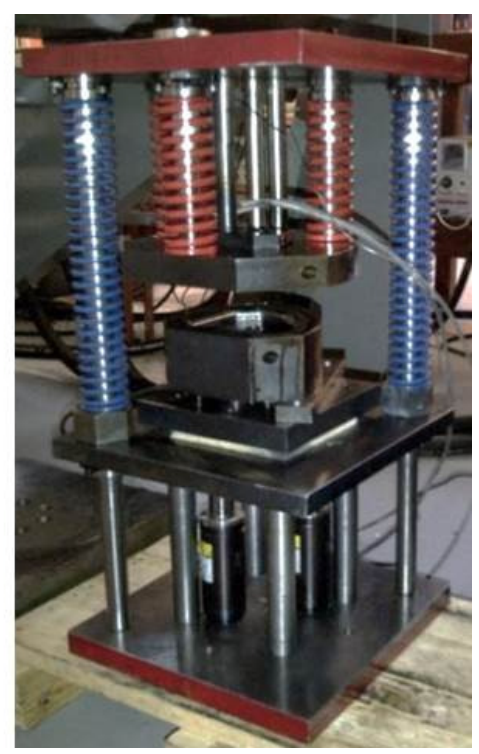

(b)

Fig. 3 - (a) 3D geometry model and (b) photograph of the forming tool [15]

2.4 Microscopy: The samples were grinded, polished and etched before microstructural observation [11]. The microstructural characterization of the samples was carried out by optical and scanning electron microscopes. All the microstructures presented in this paper were taken from longitudinal section of the strip. The grain sizes were measured from the optical microstructures. The equivalent grain diameter was calculated from the area of the selected grain as per ASTM E112 standard. For accuracy in measuring grain diameter, more than hundred readings were taken for each grain size data.

For fracture analysis a scanning electron microscope (SEM, Supra) was employed to observe the fracture surface. However, the vertical cross-section of the fractured surface was studied using an optical microscope. 


\section{Results and discussion}

\subsection{As-cast TRC and MCTRC strips}

Fig. 4 shows the polarized-light optical micrographs taken from a longitudinal cross-section of the $1.7 \mathrm{~mm}$ thick AZ31 strips produced by both TRC and MC-TRC processes. The TRC strip (Fig. 1a) has a coarse dendritic columnar grain structure with an average equivalent grain diameter of $229.67 \pm 90.59 \mu \mathrm{m}$. Detailed examination has confirmed the existence of severe central line segregation, which is rich in solute elements and usually of a eutectic composition. In contrast, the MC-TRC strip (Fig. 4b) had a fine and equiaxed microstructure throughout the entire thickness, and was free from centreline segregation. The average equivalent grain diameter of the MC-TRC strip is $76.63 \pm 18.14 \mu \mathrm{m}$.

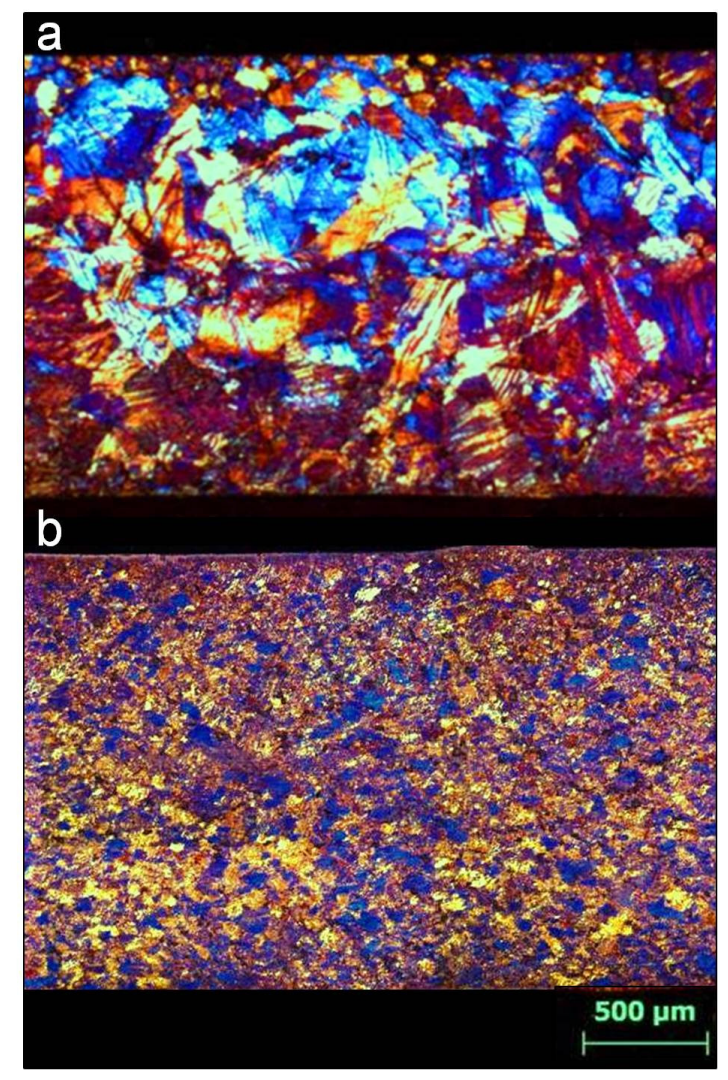

Fig. 4 - Through-thickness microstructure on a longitudinal section of AZ31 strips with $1.7 \mathrm{~mm}$ thickness produced by (a) TRC and (b) MC-TRC Fig $^{[17] .} 5$ shows the grain size

distrubustion across the thickness of the strip. It is observed that the grain size of MC-TRC strip is significantly smaller compared to the TRC strip. Also, in the case of MCTRC samples the grain size is uniform across the thickness of the strip. In the case of TRC samples grain size varies significantly across the strip thickness. Grain size is smaller near the surface and the center of TRC strips compared to the intermediate position from the center and surface of the strip. Fine grains near the surface of the TRC samples can be attributed to the chilled zone formed by the water cooled rolls, which exhibits very high cooling rate. 
Thereafter large columnar grains grow without any restriction toward the center of the strip. In this process these columnar grains pushes the solute towards the center of the strip causing an increase in solute concentration in the last solidifying liquid. Fig. 6 shows the elemental composition of the solutes obtained from SEM EDS across the strip thickness. The increase in solute concentration at the center of the strip is also responsible for fine grain structure [18].

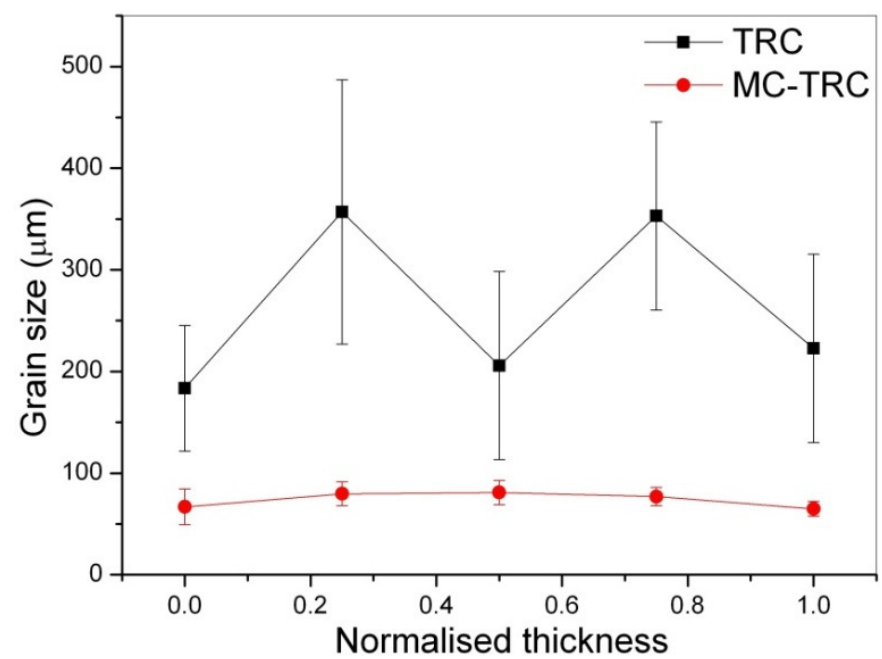

Fig. 5 Grain size distribution of TRC and MCTRC samples across the thickness of the strip

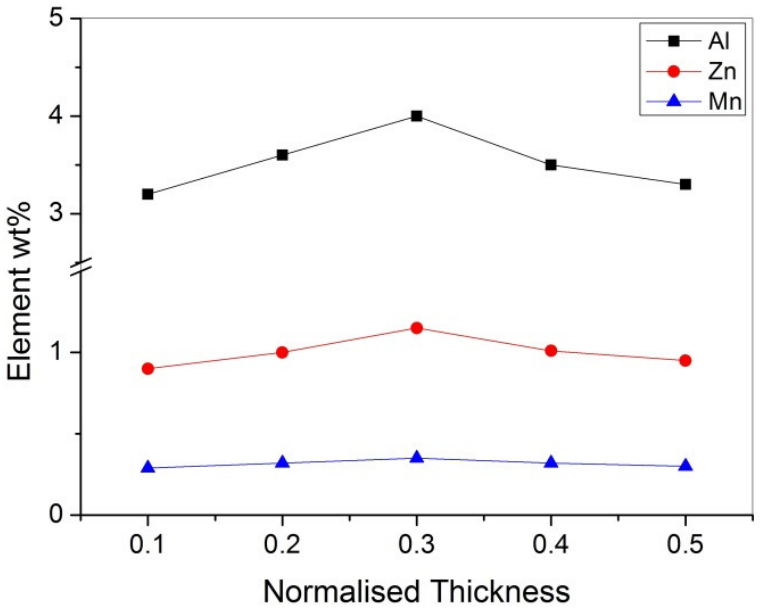

(a)

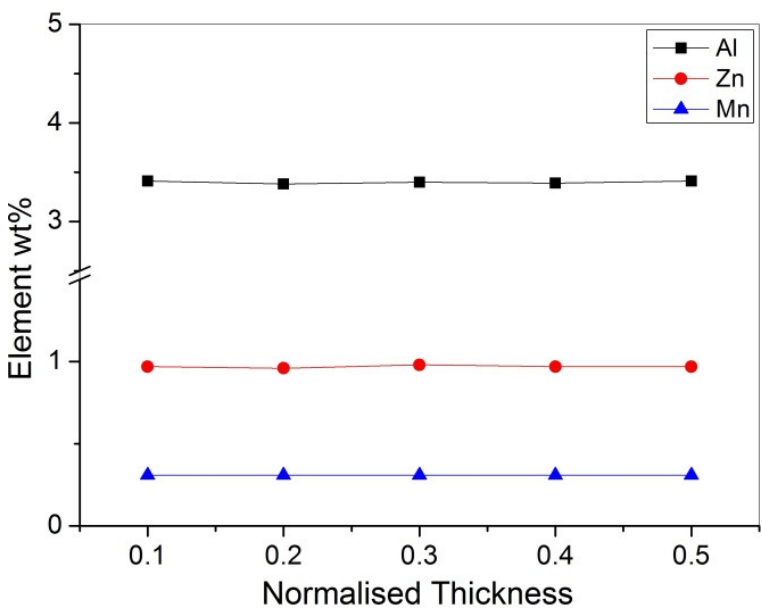

(b)

Fig. 6- Elemental composition of the solute across the strip thickness for (a) TRC and (b) MC-TRC sample

The formation of the fine and equiaxed microstructure (Fig. 4(b)) throughout the entire strip thickness of the MC-TRC strip can be attributed to the dispersion of fine $\mathrm{MgO}$ particles, which are the preferential site for nucleation during solidification. It has been discussed that oxide films formed in the melt are aggregates of 100-200 nm MgO particles. During the MC process these oxide films disintegrate into more individual particles and disperse uniformly 
throughout the melt. As the $\mathrm{MgO} / \alpha-\mathrm{Mg}$ interface is semi-coherent with small crystallographic misfit [11], $\mathrm{MgO}$ particles acts as potent nucleation sites for $\alpha-\mathrm{Mg}$ grains. The well dispersed and uniformly distributed $\mathrm{MgO}$ particles will enhance heterogeneous nucleation significantly under the relatively large cooling rate $\left(10^{3} \mathrm{~K} / \mathrm{s}\right)$ during solidification in the MC-TRC process. These potent $\mathrm{MgO}$ particles promote an advance of equiaxed solidification front rather than columnar ones. Hence, a refined uniform microstructure is observed in the case of MC-TRC strips. The absence of centerline segregation in the case of MC-TRC strips can be attributed to an equiaxed solidification front advancing from the surface to the center of the strip. Such an advancing equiaxed solidification front does not accumulate solute elements at the solidification front, and therefore does not cause centerline segregation.

The solidification process in TRC is characterized by high growth velocity and high temperature gradient, and such conditions are favorable for the development of fully columnar grain structure.

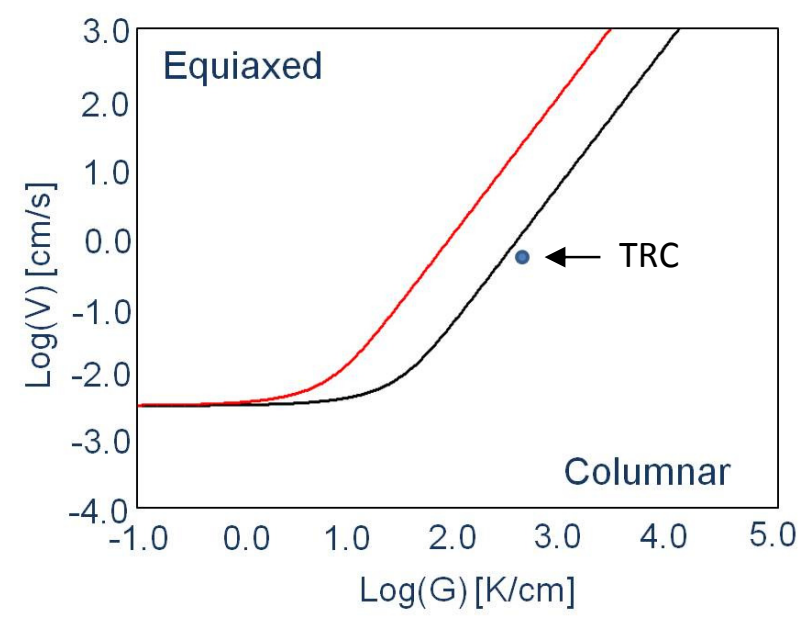

(a)

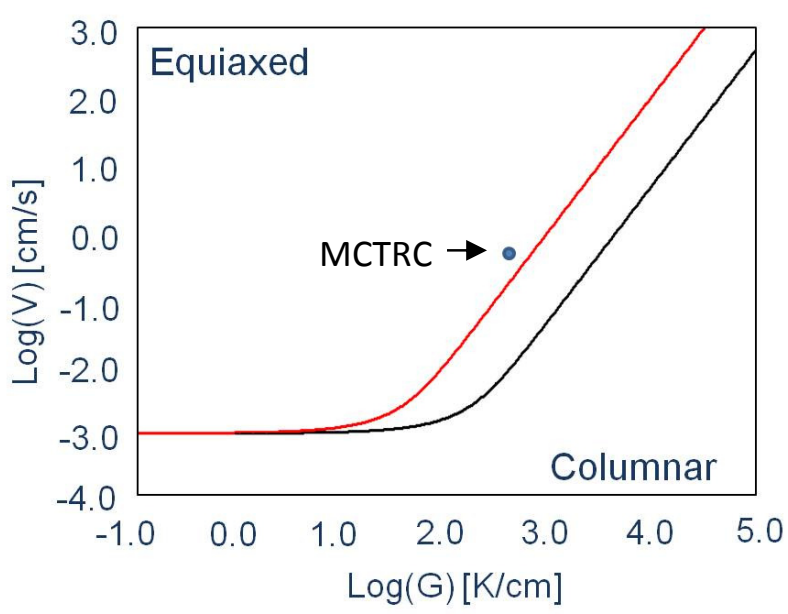

(b)

Fig. 7. Hunt map for solidification of AZ31 alloy constructed by using the model for columnar to equiaxed transition developed by Hunt [12], (a) Hunt map for solidification under normal conditions assuming that the number density for potential nucleating particles $\mathrm{N}_{0}=10^{3} \mathrm{~cm}^{-3}$ and the nucleation undercooling $\Delta \mathrm{T}_{\mathrm{N}}=1 \mathrm{~K}$. (b) Hunt map for solidification under normal conditions by assuming that the number density of potential nucleating particles $\mathrm{N}_{0}=10^{6} \mathrm{~cm}^{-3}$ and the nucleation undercooling $\Delta \mathrm{T}_{\mathrm{N}}=0.5 \mathrm{~K}$. Also shown in both maps are the calculated growth velocity $(\mathrm{V})$ and temperature gradient (G) for conventional TRC and the newly developed MC-TRC of AZ31 Mg-alloy [19].

According to the theoretical model for columnar to equiaxed transition developed by Hunt [20], a Hunt map was produced for solidification of AZ31 Mg-alloy as shown in Fig. 7(a). For the construction of Fig. 7(a), the number density of available nucleating particles is assumed to be $\mathrm{N}_{0}=10^{3} \mathrm{~cm}^{-3}$, and the undercooling for nucleation is taken as $\Delta \mathrm{T}_{\mathrm{N}}=1 \mathrm{~K}$. The experimental estimated growth velocity (V) and temperature gradient $(\mathrm{G})$ for TRC of AZ31 
alloy is shown in Fig. 3(a). The growth velocity was estimated from the geometry and casting speed of the BCAST vertical TRC machine, while the temperature gradient was estimated from the feed and solidus temperature of AZ31 alloy and the geometry of the rolls. The Hunt map in Fig. 7(a) predicts that TRC AZ31 strip with a 1.7mm gauge should have a columnar grain structure. Fig. 7(b) shows the Hunt map for solidification of AZ31 alloy with the increased nucleating sites with $\mathrm{N}_{0}=10^{6} \mathrm{~cm}^{-3}$, and the undercooling for nucleation is taken as $\Delta \mathrm{T}_{\mathrm{N}}=0.5 \mathrm{~K}$ [13]. Also shown in Fig 7(b) are the experimentally estimated growth velocity and temperature gradient for MC-TRC of AZ31 alloy, which is a physical approach to grain refinement as will be discussed in this paper later. The Hunt map in Fig 7(b) predicts that TRC of AZ31 alloy with adequate nucleation sites produces a fully equiaxed grain structure.

A physical approach to grain refinement by MC process has been developed to provide grain refinement without addition of chemical grain refiners. Mg-alloy melts inevitably contain oxides, which normally exist in alloy melts in the form of composite films containing densely populated nanometre-scale $\mathrm{MgO}$ particles in a liquid matrix [11]. It is found that $\mathrm{MC}$ provided by the twin screw mechanism [11] can effectively disperse such oxide films into discrete $\mathrm{MgO}$ particles, giving rise to an increase of $\mathrm{MgO}$ number density by three orders of magnitude [13]. It has been confirmed that $\mathrm{MgO}$ does nucleate $\alpha-\mathrm{Mg}$ during solidification of Mg-alloys [11]. This means that grain refinement of Mg-alloy can be achieved by introducing MC process prior to TRC.

The TRC and MC-TRC results shown in Fig. 4 evidently follows the theoretical prediction based on Hunt's model. In the MC-TRC process, Mg-alloy melt has been intensively sheared to enhance nucleating particles with adequate number density, suitable size and distribution. The solidification mechanism in TRC and MC-TRC process is explained in section 3.3 .

\subsection{Homogenization treatment}

The samples subjected to homogenization treatment and the microstructures of TRC and MCTRC samples homogenized for 15 and 60 minutes are shown in Fig. 8. Large columnar grains and centerline segregation are observed in the case of TRC sample even after 60 minutes of homogenization treatment (Fig. 8(b)). Some fine grains were observed at the grain boundaries of large grains (Fig. 8(b)). These fine grains were formed by recrystallization process during homogenization treatment. However, the amount of fine recrystallized grains is very less, which suggests that there was an insignificant amount of stored energy in TRC 
samples to trigger nucleation of fresh grains. This can be attributed to the minimum amount of deformation during TRC process. Fine equiaxed recrystallized grains were observed in the case of MCTRC sample just after 15 minutes of homogenization treatment (Fig. 8(c)). In contrary to TRC strips, MCTRC strips underwent higher amount deformation during the casting process.

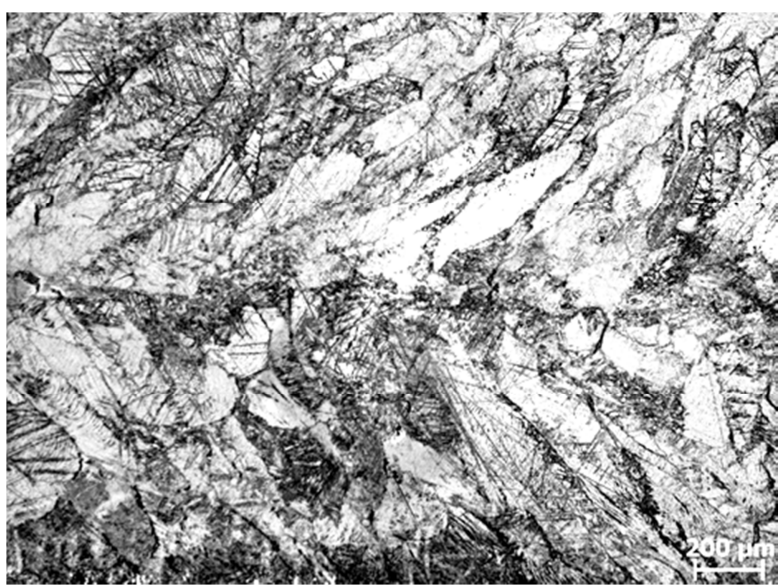

(a)

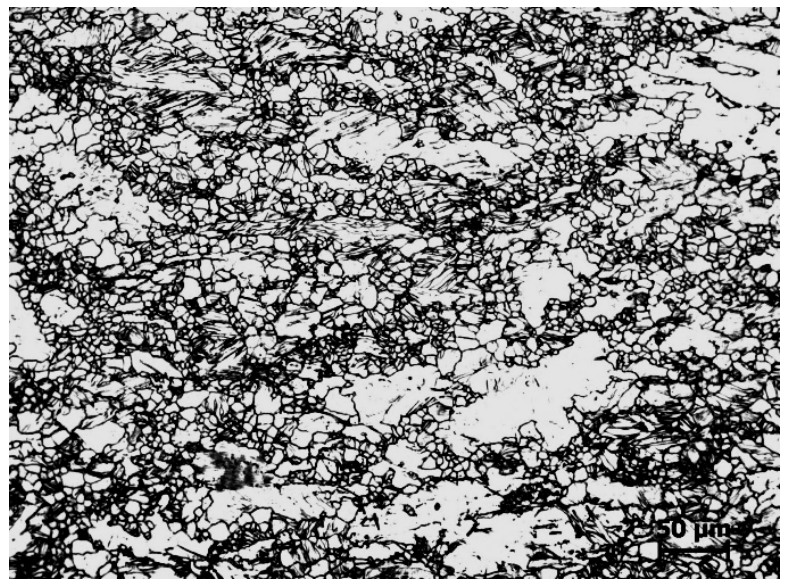

(c)

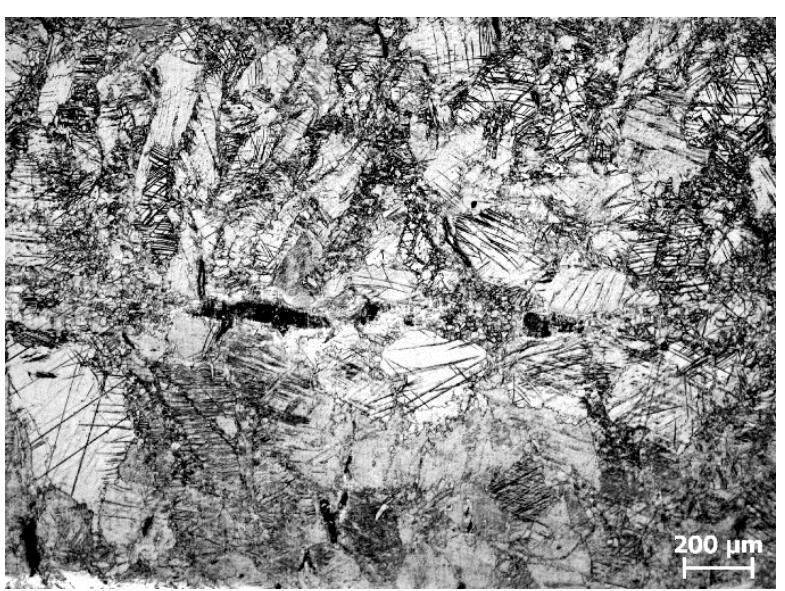

(b)

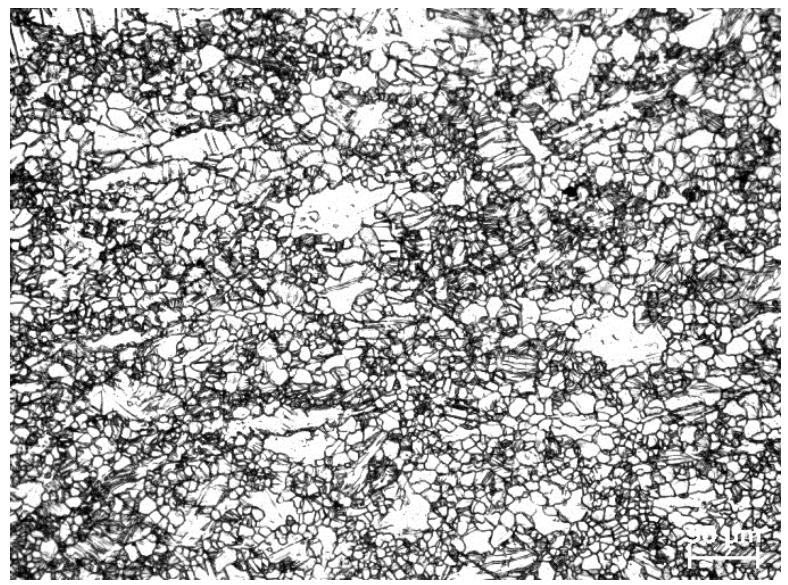

(d)

Fig. 8 - Optical microstructure of heat treated (a, b) TRC strip and (c, d) MCTRC strip at 15 and 60 minutes, respectively.

The details of the grain size variation with homogenization treatment time for TRC and MCTRC samples are shown in Fig. 9. As discussed earlier the grain size of TRC samples were much higher compared to MCTRC samples. Also the standard deviations shows TRC samples have significant variation in grain size compared to MCTRC samples. There is an asymmetrical decrease in grain size in the case of TRC samples till 120 minutes of homogenization treatment. Whereas, the grain size of MCTRC samples, drastically drops just after 15 minutes of homogenization treatment. More interestingly there is no significant grain 
growth thereafter. This can be attributed to the pinning action of oxide particles, which restricts the grain growth [21]. Percentage recovery during recrystallization was calculated for each sample. For TRC samples maximum recovery during recrystallization process was $56.7 \%$ after $3 \mathrm{hrs}$ of homogenization treatment. However, for MCTRC samples $100 \%$ recovery was achieved only after 15 minutes of homogenization treatment.

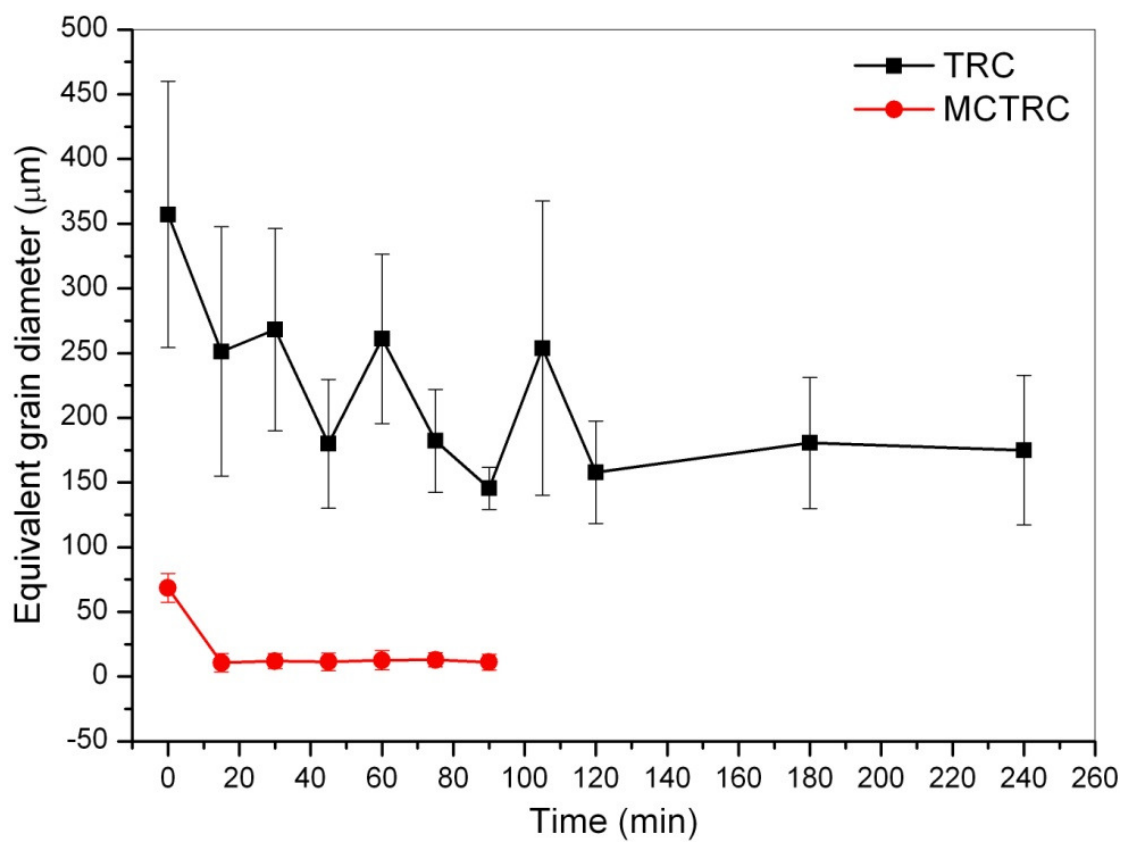

Fig. 9 - Variation in grain size with homogenization treatment time for TRC and MCTRC samples

\subsection{Solidification and deformation mechanism of TRC and MCTRC samples}

Fig. 10 illustrates the solidification mechanism during TRC and MCTRC process. As discussed earlier in the case of TRC columnar grains start forming near the roll surface towards the centre of the strip. During growth these columnar grains rejects the solutes atoms towards the centre of the strip, which drops the liquidus temperature of the melt at the centre of the strip. This results in an increase in the sump depth as shown in Fig. 10(a). Hence, the deformation region significantly decreases during TRC process. On the other hand, in the case of MCTRC samples heterogeneous nucleation by oxide particles dominates the solidification mechanism. It has been established earlier that $\mathrm{MgO}$ particles are potent nuclei for $\alpha$-magnesium. This results in the advance of an equiaxed solidification front from the roll surface to the centre of the strip instead of columnar grain growth. The solute rejection towards the centre of the strip is insignificant and hence the sump depth less in the case of MC-TRC compared to the TRC process (Fig. 10(b)). Hence, the deformation region extends as the sump depth decreases. MCTRC strips undergo higher degree of deformation during the 
casting process in comparison to TRC strips. It has been found stated earlier that the point of complete solidification to the exit point of the strip, the rolling force $(F)$ can be calculated by [22]

$$
F=1.55 \sigma_{\text {yield }} W\left[1+\frac{\sqrt{R\left(h_{2}-h_{1}\right)}}{4\left(h_{1}-\frac{h_{\text {mean }}}{2}\right)}\right] \sqrt{R\left(h_{2}-h_{1}\right)}
$$

Where

$$
h_{\text {mean }}=\left[h_{1}-\frac{\left(h_{2}-h_{1}\right)}{2}\right]
$$

$\sigma_{\text {yield }}$ is mean yield stress, $W$ is width of the strip, $R$ is outer radius of the rolls, $h_{1}$ is thickness of the strip at the point of complete solidification, $h_{2}$ is thickness of the strip at the exit point and $h_{\text {mean }}$ is mean thickness of the strip. From equation (1) it can be deduced that the difference in the rolling force for different alloys would come from the yield stress term. For higher alloying addition the rolling force would increase as the yield stress would increase. As the alloy is same in the present case, $h_{1}$ and $h_{2}$ values influences the rolling force (F) significantly. From schematic diagram (Fig. 10) and equation (1) it can be conclusively stated that MC-TRC strips experience higher amount of deformation compared to TRC strips. During experiments an increase in torque of the rolls was also noticed. It can be attributed to the increase in the deformation of MC-TRC AZ31 alloy during the process.

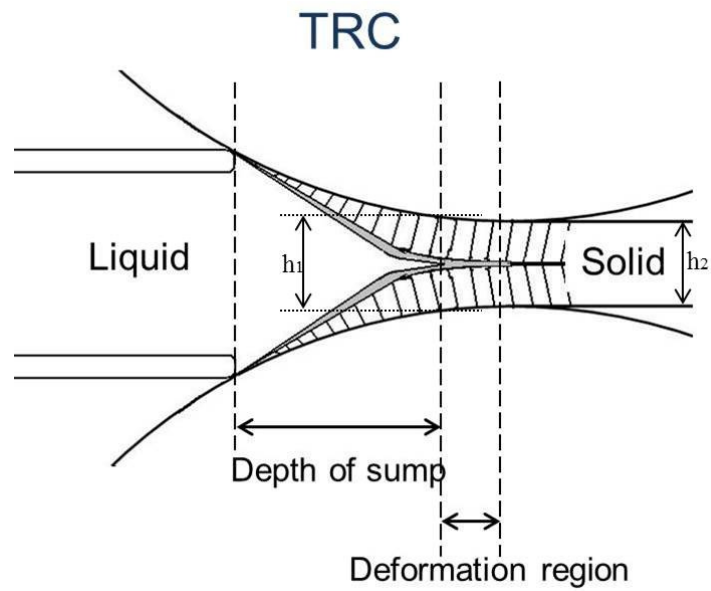

(a)

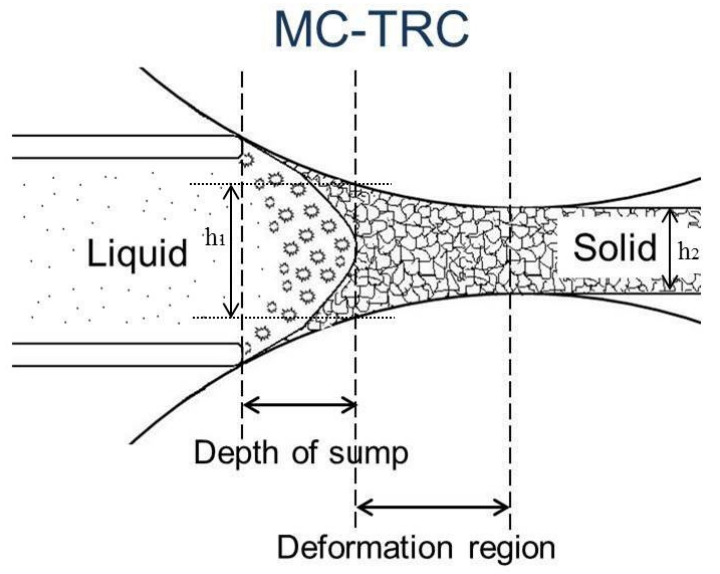

(b)

Fig. 10 - Schematic illustrating the solidification mechanism for (a) TRC and (b) MCTRC samples 


\subsection{Mechanical properties}

The selection criteria for the samples of tensile tests have been uniform grain size and microstructure for both TRC and MCTRC samples. It was found that in the case of TRC samples maximum recovery during recrystallization was obtained at three hours of homogenization treatment. However, in the case of MCTRC samples uniform and small grain structure was obtained just after 15 minutes of homogenization. As the samples used for homogenization treatment were significantly smaller in dimension compared to the strips used for preparing tensile and hot stamping samples, one hour homogenization time was selected for MC-TRC samples.

Table 1 shows the results obtained from tensile tests for TRC and MCTRC samples. Both TRC and MCTRC samples have comparable tensile strengths and elongations at various test temperatures. At $250^{\circ} \mathrm{C}$, MCTRC samples show significant improvement in elongation compared to TRC samples. It can be attributed to the uniform and fine grain structure obtained by MC-TRC after homogenization treatment. However, it is observed both TRC and MC-TRC samples had comparable tensile strength at elevated temperatures $\left(300-400^{\circ} \mathrm{C}\right)$. And the percentage elongations of MC-TRC samples are slightly better than TRC samples. To understand the deformation mechanism during the tensile tests, the fracture surface and sub-surface were examined by scanning electron and optical microscopy, respectively.

Table 1 - Results of tensile tests carried out a strain rate of $1 \mathrm{~s}^{-1}$

\begin{tabular}{ccccc}
\hline Test & \multicolumn{2}{c}{ TRC } & \multicolumn{2}{c}{ MCTRC } \\
\cline { 2 - 5 } Temperature $\left({ }^{\circ} \mathrm{C}\right)$ & UTS (MPa) & \% Elongation & UTS (MPa) & \% Elongation \\
\hline 250 & 215.54 & 20.64 & 239.76 & 41.59 \\
300 & 160.75 & 48.46 & 152.46 & 50.18 \\
350 & 118.67 & 61.87 & 118.02 & 66.62 \\
400 & 109.09 & 91.85 & 88.09 & 102.37 \\
\hline
\end{tabular}

Fig. 11 shows scanning electron microstructures of the fracture surfaces of the TRC and MCTRC samples tested at $300^{\circ} \mathrm{C}$ and $400^{\circ} \mathrm{C}$. Dimples and cleavage planes are observed in all the microstructure. This shows both TRC and MC-TRC samples have undergone a mixed mode of failure [23]. As the dimples on the fracture surface is more significant, it can be concluded that the deformation of the samples was dominated by ductile mode. Evidence of plastic flow is also observed in MC-TRC samples tested at $400^{\circ} \mathrm{C}$ Fig. $11(\mathrm{~d})$. This shows super plastic behaviour of MCTRC strip at $400^{\circ} \mathrm{C}$. However, TRC samples did not show such behaviour 
(Fig. 11(c)). To understand more about the deformation behaviour during tensile test, vertical section of fracture surface was also studied.

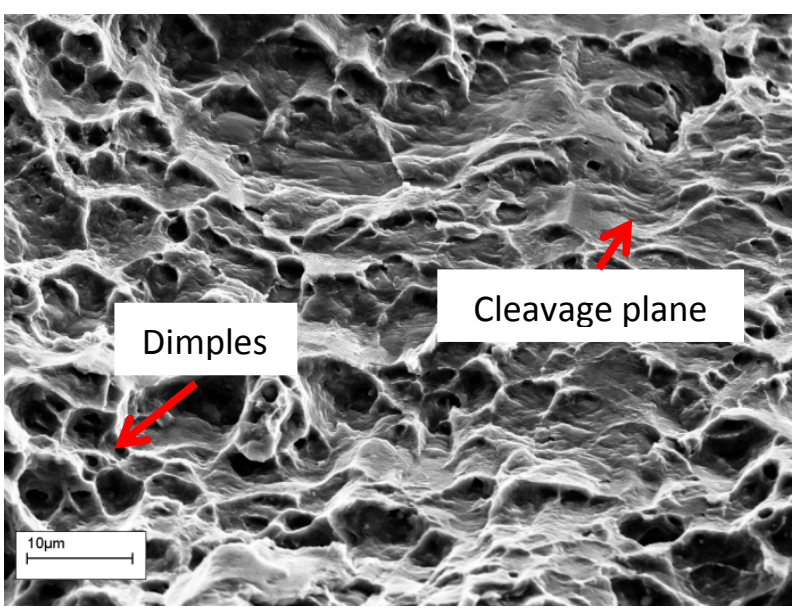

(a)

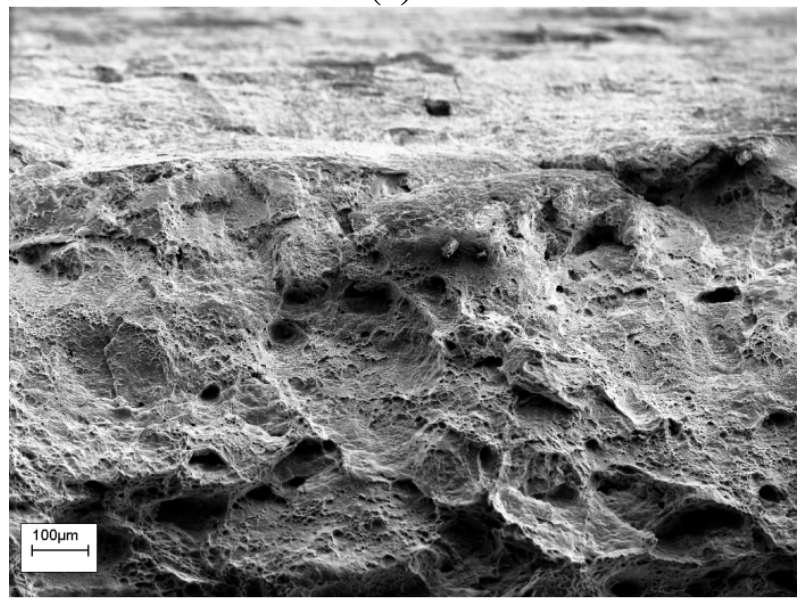

(c)

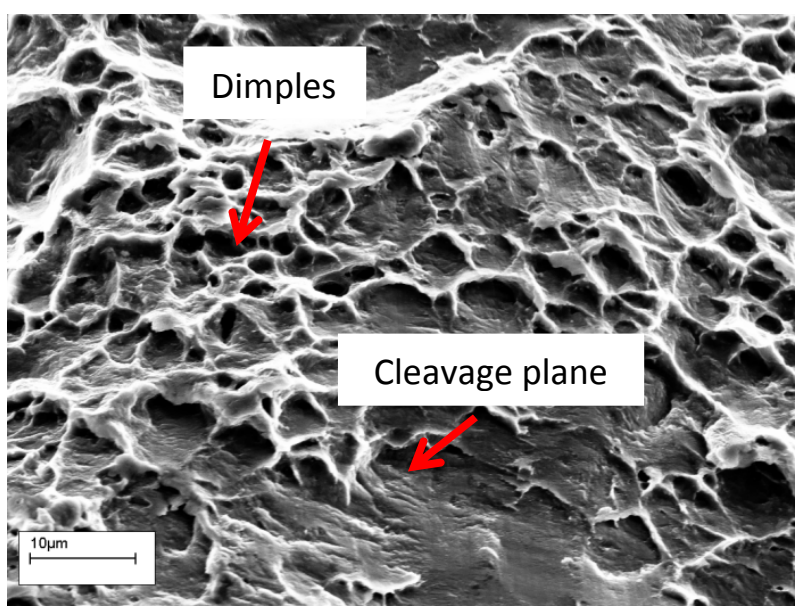

(b)

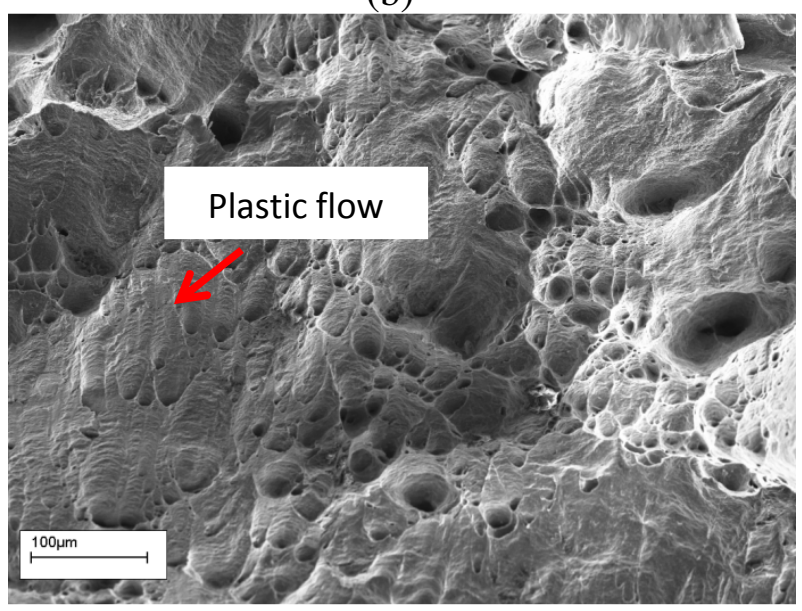

(d)

Fig. 11 - Scanning electron microstructures of the fractured tensile surfaces of (a and c) TRC and (b and d) MC-TRC samples tested at 300 and $400^{\circ} \mathrm{C}$, respectively.

Fig. 12, shows the microstructure of the vertical section of fractured TRC and MCTRC tensile test sample at different test temperature. It is clearly evident (Fig. 12(a and b)) that at elevated temperature grains elongates for both TRC and MC-TRC samples. Fig. 12(a) shows large grains also deforms and elongates towards the tensile direction. This explains the comparable results presented in table 1 for TRC and MC-TRC samples at temperatures 300$400^{\circ} \mathrm{C}$. At temperature above $300^{\circ} \mathrm{C}$ influence of grain size on deformation behaviour seems insignificant. This can be attributed to the deformation driven by slipping of atomic planes at elevated temperatures. It has been earlier found that non-basal slip system activates at elevated temperature and it improves the ductility of Mg Alloys [24-32]. The evidence of slip induced deformation is clearly observed as parallel lines within the grains (Fig. 12(b)) in the 
case of MC-TRC sample tested at $350^{\circ} \mathrm{C}$. Also, very fine grains surrounding the large deformed grains were observed in the samples tested in $350-400^{\circ} \mathrm{C}$ of varying amount and size. Fig 12(b and c) shows the fine grains surrounding large deformed grains. These fine grains are formed during tensile test due to strain induced dynamic recrystallization process. The formation of very fine recrystallized grains during tensile test can also contribute in deformation of the samples. The presence of fine grains in the grain boundaries of larger grains will assist in grain boundary sliding at elevated temperature. Hence, these fine grains act as a lubricant during grain boundary sliding [33]. Not only strain induced dynamic recrystallized grains were observed in these samples but strain induced grain growth was also evident. Systematic grain size measurements were carried out to understand the strain induced grain growth of during tensile test. It was observed that recrystallized grain size increases with increase in the amount of straining. Fig. 12(d) shows the coarse equiaxed grains at the fracture tip of MC-TRC tensile test sample tested at $400^{\circ} \mathrm{C}$. This can be attributed to the strain induced grain coarsening of the recrystallized grains. Hence, strain induced nucleation of fresh grains and grain growth takes place during the tensile test process at elevated temperature for twin roll cast AZ31 alloy.

Fig. 13 shows the verticle section microstructure of the fractured tensile samples. A elongaled pore is observed inside the tensile sample parrallel to the tensile direction. These elongated pores parallel to the tensile directions were observed both in TRC and MCTRC samples. The presence of such porosity during forming process of the strips is not desired as they lead premature failure of the strips during forming process. However, from the results it was confirm that the location of the pores are more important. The pores inside the sample have insignificant influence in catastrophic failure during tensile testing compared pores near or on the surface of the strip. The probable solution to such defects could be one or two passes of hot rolling after TRC or MCTRC process. 


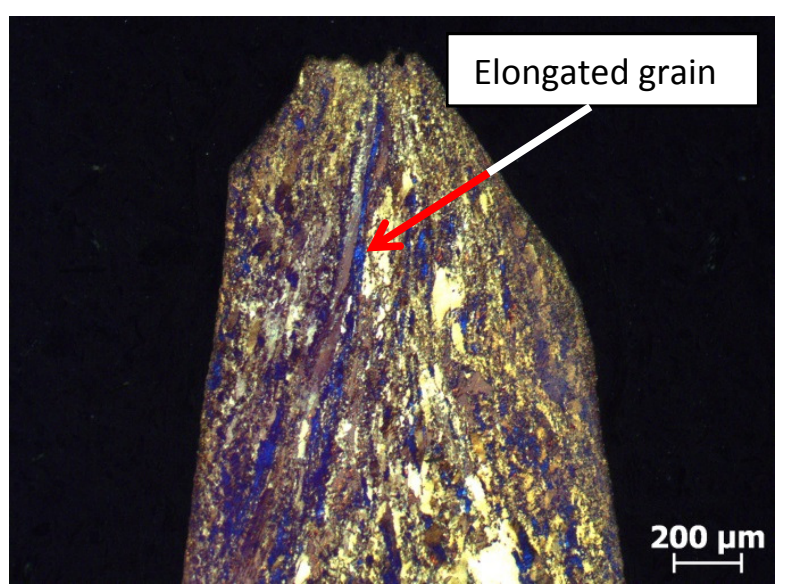

(a)

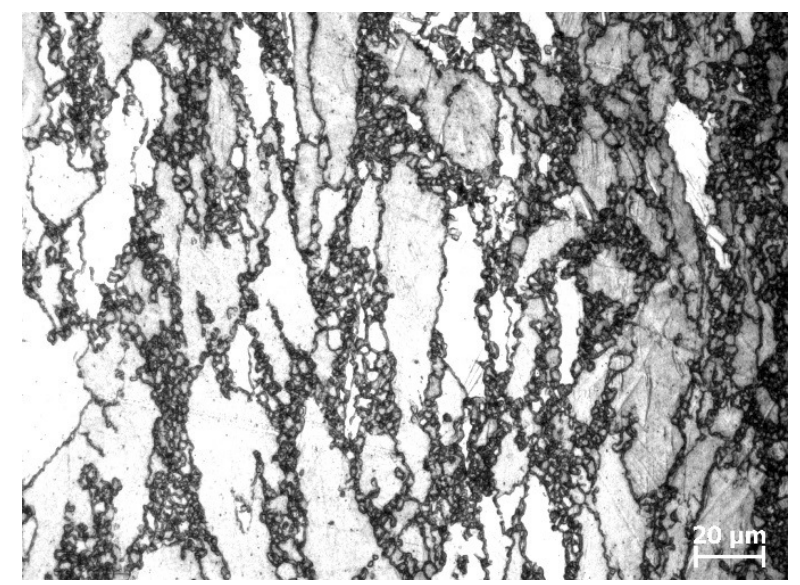

(c)

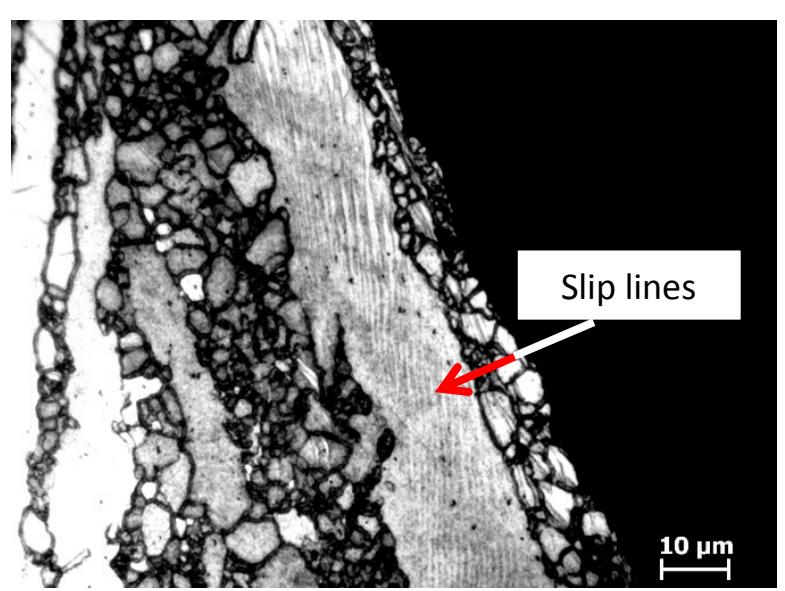

(b)

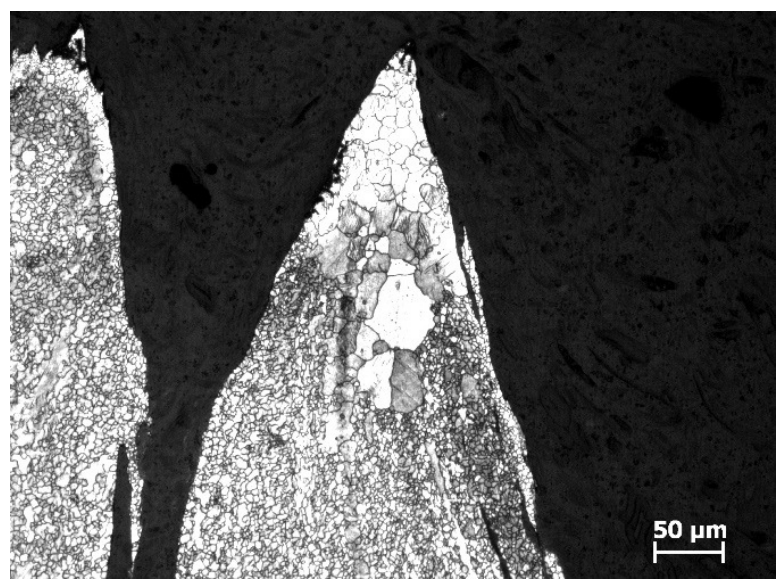

(d)

Fig. 12 -Vertical section microstructures of fractured tensile samples of (a) TRC sample tested at $400^{\circ} \mathrm{C},(\mathrm{b}, \mathrm{c}) \mathrm{MCTRC}$ sample tested at $350^{\circ} \mathrm{C}$, (d) MCTRC sample tested at $400^{\circ} \mathrm{C}$

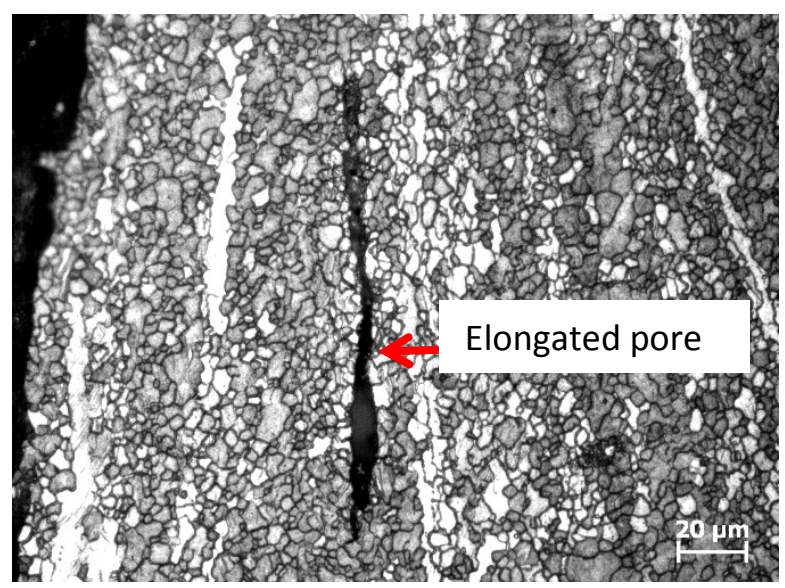

Fig. 13 - Optical microstructure showing pore elongation in tensile test direction

Fig. 14 shows photographs of homogenized TRC and MC-TRC strips hot stamped at $400{ }^{\circ} \mathrm{C}$. After stamping, the TRC strip shows few cracking at regions that underwent a large amount 
deformation (Fig. 10a). This can be attributed to the inconsistency in grain size and presence of centreline segregation in homogenized samples. It is interesting to note that the stamped MC-TRC strip shows a smooth stamped surface and that no sign of any cracking is observed (Fig. 10b). The hot stamping trials have demonstrated clearly that the MC-TRC process can produce Mg-alloy strips with high enough deformability for direct hot stamping without hot rolling.

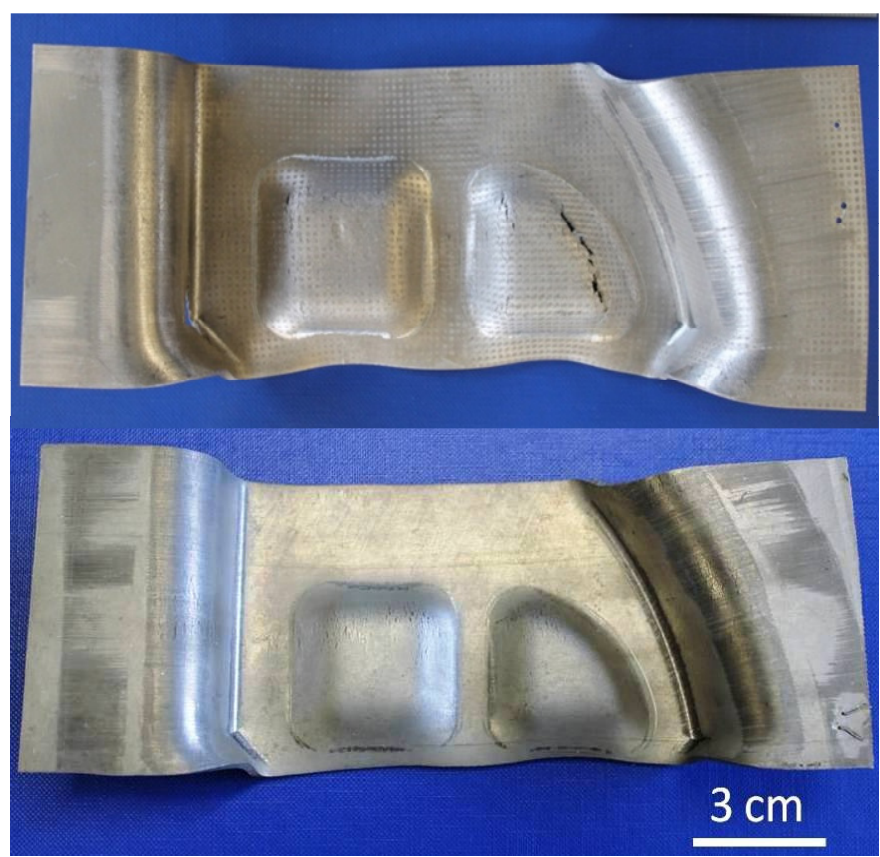

Fig. 14 - Photographs of AZ31 Mg components stamped directly from homogenized (a) TRC strip and (b) MC-TRC strip. Stamping was carried out at $400{ }^{\circ} \mathrm{C}$ on both TRC and MC-TRC strips of $1.7 \mathrm{~mm}$ thickness in the as-cast condition.

\section{Conclusions}

MC-TRC process can disintegrate and disperse $\mathrm{MgO}$ particle films and agglomerates in fine nano-sized particles into the melt. These $\mathrm{MgO}$ particles acts as a nucleating sites for $\alpha-\mathrm{Mg}$ and hence very fine uniform and equiaxed grain are formed in MC-TRC process. The homogenization of TRC samples takes significantly longer time compared to MC-TRC samples. Microstructures of homogenized samples reveals that MC-TRC strips have undergone higher degree of deformation compared to TRC strips. It has been attributed to the different solidification mechanism for TRC and MC-TRC strips. In the case of TRC sample, columnar grains grow from the surface of the roll to interior, which is also responsible for solute segregation at the centre of the strip. Whereas, in the case of MC-TRC sample equiaxed solidification front grows from the roll surface towards the centre of solidifying strip. 
After homogenization TRC and MC-TRC showed comparable mechanical properties at higher temperature $\left(300-400^{\circ} \mathrm{C}\right)$. However, at $250^{\circ} \mathrm{C}$ MC-TRC sample showed better strength and ductility. This was attributed to the fine grain structure of MC-TRC samples. Analysis of fracture surface and sub-surface revealed that at elevated temperature grain size becomes less relevant in deformation process.

Strain induced recrystallization and growth was observed during tensile tests. It was also conclusively found that the dynamic recrystallization and growth helps in deformation process. Pores present on and near the surface is more detrimental compared to pores present inside the strips.

The homogenized MC-TRC strips can be successfully hot-stamped into engineering components without prior hot rolling. Whereas the TRC samples despite of good tensile properties, fails during hot stamping process.

\section{Acknowledgement}

This work is financially supported by EPSRC - LiME, UK and Towards Affordable, ClosedLoop Recyclable Future Low Carbon Vehicle Structures - TARF-LCV (EP/I038616/1). I would like to thank Department of Mechanical Engineering, Imperial College London, UK for allowing us to use their laboratory facilities for materials testing. Special thanks to Mr. Steve Cook, Mr. Peter Lloyd, Mr. Graham Mitchell and Mr. Carmelo for their technical support for MC-TRC equipment and process at BCAST, Brunel University London. 


\section{References}

[1] S. Lee, Y.H. Chen, J.Y. Wang, Isothermal sheet formability of magnesium alloy AZ31 and AZ61, J. Mater. Process. Technol. 124 (2002) 19-24.

[2] H. Takuda, T. Enami, K. Kubota, The formability of a thin sheet Mg-8.5Li-1Zn alloy, J. Mater. Process. Technol. 101 (2000) 281-286.

[3] H. Takuda, H. Fujimoto, N. Hatta, Modelling on flow stress Mg-Al-Zn alloys at elevated temperatures, J. Mater. Process. Technol. 80-81 (1998) 513-516.

[4] N. Stanford, M.R. Barnett, Fine grained AZ31 produced by conventional thermomechanical processing, J. Alloy. Compd. 466 (2008) 182-88.

[5] M.R. Barnett, N. Stanford, P. Cizek, A. Beer, Z. Xuebin, Z. Keshavarz, Mechanism of deformation in magnesium alloys and the challenge of extending room temperature plasticity, JOM61 (2009) 19-24.

[6] M. Ferry, Direct strip casting of metals and alloys, Woodhead Publishing Ltd., Cambridge, 2006.

[7] M. Masoumi, F. Zarandi and M.O. Pekguleryuz, Alleviation of basal texture in twinroll cast Mg-3Al-1Zn alloy, Scripta Materialia, 62 (2010) 823-826.

[8] D. Liang, W. Borbidge, D.R. East, R.V. Allen: US Patent No.7,028,749 B2, 2006.

[9] Z. Fan, Y. Wang, M. Xia, S. Arumuganathar, Enhanced heterogeneous nucleation in AZ91D alloy by intensive melt shearing, Acta Materialia 57 (2009) 4891-4901.

[10] Z. Fan, G. Liu, Solidification behaviour of AZ91D alloy under intensive forced convection in the RDC process, Acta Mater. 53 (2005) 4345-4357.

[11] I. Bayandorian, Y. Huang, Z. Fan, S. Pawar, X. Zhou, G.E. Thompson, The impact of melt conditioned twin-roll casting on the downstream processing of an AZ31 magnesium alloy, Metall. Mater. Trans. A 43 (2012) 1035-1047.

[12] Yinong Wang, Suk Bong Kang, Jaehyung Cho, Microstructure and mechanical properties of $\mathrm{Mg}-\mathrm{Al}-\mathrm{Mn}-\mathrm{Ca}$ alloy sheet produced by twin roll casting and sequential warm rolling, Journal of Alloys and Compound, 509 (2011) 704-711.

[13] M. Masoumi, F. Zarandi and M.O. Pekguleryuz, Microstructure and texture studies on twin-roll cast AZ31 (Mg-3wt.\%Al-1wt.\%Zn) alloy and the effect of thermomechanical processing, Materials Science and Engineering A, 528 (2011) 1268-1279.

[14] Kyun-Hun Kim, Byeong-Chan Suh, Jun Ho Bae, Myeong-Shik Shim, S. Kim and Nack J. Kim, Microstructure and texture evolution of Mg alloys during twin-roll casting and subsequent hot rolling, Scripta Materialia, 63(2010) 716-720.

[15] Omer El Fakir, Liliang Wang, Daniel Balint, John P. Dear, Jianguo Lin, Numerical study of the solution heat treatment, forming, and in-die quenching (HFQ) process on AA5754, 87 (2014) 39-48.

[16] O. El Fakir, S. Das, I. Stone, G. Scamans, Z. Fan, L. Wang, D. Balint, J. P. Dear, J. Lin, Solution heat treatment, forming and in-die quenching of a commercial sheet magnesium alloy into a complex-shaped component: experimentation and FE simulation, Materials Science Forum, 622-633 (2014) 596-602.

[17] Sanjeev Das, Shouxun Ji, Omer El Fakir, Liliang Wang, John Dear, Jianguo Lin, Ian Stone, Geoff Scamans, Zhongyun Fan, Melt Conditioned Twin Roll Casting (MC-TRC) of 
Thin Mg-Alloy Strips for Direct Stamping of Mg Components, Materials Science Forum, 765 (2013) 170-174.

[18] Y.C. Lee, A.K. Dahle and D.H. StJohn, The role of solute in grain refinement of magnesium, Metallurgical and Materials Transactions A, 31A (2000) 2895-2906.

[19] Sanjeev Das, Nilam Barekar, and Zhongyun Fan, Solidification Mechanism of the Melt Conditioned Twin Roll Cast Magnesium Alloy, Materials Science Forum, 790-791 (2014) 291-295.

[20] J. D. Hunt, steady state columnar and equiaxed growth of dendrites and eutectic, Materials Science and Engineering, 65 (1984) 75-83.

[21] C.S. Smith, Trans. Am. Inst. Min. Metall. Eng. 175 (1984) 15.

[22] N.S. Barekar and B.K. Dhindaw, Twin-roll casting of aluminium alloys - An Overview, Materials and Manufacturing Process 29 (2014) 651-661.

[23] Wang Bai-Shu, Xiong Shou-mei, Liu Yong, Tensile fracture of as-cast and hot rolled $\mathrm{Mg}-\mathrm{Zn}-\mathrm{Y}$ alloy with long-period stacking phase, Trans. Non Ferrous, Met. Soc. China 20 (2010) s488-s492.

[24] Jae-Hyung Cho and Suk-Bong Kang, Deformation and recrystallization behaviour in magnesium alloys, Recent Developments in the study of recrystallization, Feb 6, 2013, Intech.

[25] Bakarian, P.W., and Mathewson, C.H., Slip and twinning of magnesium single crystals at elevated temperatures, Trans. AIME, 1943, 152, pp. 226.

[26] Burke, E.C., and Hibbard, W.R., Jr., Plastic deformation of magnesium single crystals, Trans. AIME, 1952, 194, pp. 295-303.

[27] Hauser, F.E., Starr, C.D., Tietz, L., Dorn, J.E., Deformation mechanisms in polycrystalline aggregates of magnesium, Trans. ASM, 1955, 47, pp. 102-103.

[28] Kleiner, S., Uggowitzer, P.J., Mechanical anisotropy of extruded Mg-6\% Al-1\% Zn alloy, Mater. Sci. Eng. A, 2004, 379, pp. 258-263.

[29] Reed-Hill, R.E., A study of the $\left\{101^{-} 1\right\}$ and $\left\{101^{-} 3\right\}$ twinning modes in magnesium, Trans. AIME, 1960, 218, pp. 554-558.

[30] Reed-Hill, R.E., Robertson, W.D., Additional modes of deformation twinning in magnesium, Acta Metall., 5, 1957, 5, pp. 717-727.

[31] Reed-Hill, R.E., Robertson, W.D., Deformation of magnesium single crystals by nonbasal slip, Trans. AIME, 1957, 209, pp. 496-502.

[32] Reed-Hill, R.E., Robertson, W.D., Pyramidal slip in magnesium, Trans. AIME, 1958, 212, pp. 256-259.

[33] Trojanova Zuzanka, Donic Tibor, Lukac Pavel, Palcek Peta, Chalupova Maria, Tillova Eva, Bastovansky Ronald, Tensile and fracture properties of Mg-RE-Zn alloy at elevated temperature, Journal of Rare Earths 32 (2014) 564-572. 